\title{
OCTA 2006: the unfulfilled promise
}

\author{
Petrus C. van Duyne
}

Published online: 14 July 2007

(C) Springer Science + Business Media, LLC 2007

\section{Looking forward}

"I am delighted to present the public version of the first European Union's Organised Crime Threat Assessment (OCTA). The OCTA is a core product of the intelligence led policing concept and its drafting is one of Europol's top priorities in 2006." With these words the director of EUROPOL, Mr. Peter Ratzel, welcomed the long awaited approach to assess the threatening impact of organised crime in the European Union. The organised crime threat assessment approach was developed because the European Council felt a need for a more future oriented assessment of organised crime. Merely describing the annual situation of what law enforcement agencies discovered about 'organised crime' was increasingly experienced as unsatisfactory. Thus, in 2004 the European Council decided to adopt a future oriented, pro-active approach. Consequently a working group consisting of representatives of the Member States was established out of which a special technical group was formed to deal with the hard core of OCTA: the instrument with which to determine something like an 'organised crime' threat. That instrument should consist of a questionnaire to be sent to law enforcement agencies, while also partners from the private sectors and academia would be approached. This resulted in OCTA 2006 of which a public version has been issued in the fall of that year.

OCTA does not stand alone. There are other reports on the organised crime situation in various jurisdictions. To value the OCTA 2006 it may be proper to compare this product with some other 'organised crime' assessments, like the annual organised situation report of the German Bundeskriminalamt or a non-European organised crime assessment in order not to focus on Europe alone.

P. C. van Duyne $(\bowtie)$

Penal Law Department, Universiteit van Tilburg, Postbus 90153, Tilburg, LE 5000, The Netherlands e-mail: Petrus@uvt.nl 
Naturally, a public report of a public international body should meet proper standards, particularly when it touches such a serious topic as the threat emanating from 'organised crime.' Therefore the following questions must be addressed:

- Are its statements coherent and are its conclusions supported by a proper methodology and reliable evidence?

- To what extent does the OCTA perform better than the descriptive organised crime situation reports?

In short, this approach, to which all who deal with the purported phenomenon of 'organised crime,' have been looking forward, must have some added value. At least as a threat assessment it must keep its promise of "closing the gap between strategic findings and operational activities."

\section{Accountability under threat}

The first question a reviewer must raise is not whether the findings are interesting, surprising or expected, but how they are arrived at. There must be a transparent road from the assumptions to the outcomes and its conclusions must be deduced from those outcomes. Findings and conclusions must be accounted for. The fulfilment of this requirement must be examined first. Later I will turn to such issues like the internal coherence in the formulation of findings and conclusions.

About this accountability I can be short: there is none. The reader is supposed to feel satisfied with the statement: "The OCTA is based on a multi-source approach, including law enforcement and non-law enforcement sources. These sources include various European agencies as well as the private sector. A specific emphasis is put on elaborating the benefits of an intensified public-private partnership." What the input of the various law enforcement agencies and private sector is remains hidden. What are these benefits and how have they been elaborated? The reader is not informed. How the OCTA input has been acquired, by interviews or questionnaires, is likewise not revealed. A questionnaire has been used indeed, but Europol turned down my request to make use of that document. Hence, there is no way to determine the reliability of the data input, the processing of the data, and therefore the reliability of the findings and the validity of the conclusions about the stated threats.

About other aspects of the methodology only 'slips of the tongue' revealed that reader's suspicions are fully justified. For OCTA 2007 improvements were expected, because "the Member States' involvement would be better for which reason the input would be better too." Hence, the reader can only surmise that methodologically OCTA 2006 leaves much to be desired. But what went wrong and what and how things will be improved, that is 'classified' information.

Obviously the key instrument is the questionnaire which is 'classified' (even a blank version is confidential). However, judging from what I have learned about the 2007 questionnaire (which I did not receive from a person I did not know), there is much to be improved for 2008 too. The 2007 questionnaire is unwieldy, impractical, user-unfriendly and frequently ambiguous in its wording. For example, 'criminal 
groups' and 'syndicates' are used alternately as if they have the same meaning. To overcome this impediment, the questionnaire is adorned with dozens of lengthy footnotes (about 50). Conceivably this will increase the workload of the officers who must process them, while it adds ambiguity rather than providing precise explanations.

Indeed, this secret methodology begs for disclosure.

\section{Organised crime: the obvious and more than obvious}

One thing should be valued as positive: the OCTA 2006 does not reopen the debate on what 'organised crime' is supposed to be. It does not even refer to a definition, let alone discuss it. Apparently it assumes that the reader knows it has adopted the EUdefinition and that the reader knows its contents too. Thus, the rapport does not loose time and comes strait to the point: "OC is prevalent in all Member States (MS) and increasingly international in its composition." Subsequently we get an exposé of the various crime-regions in Europe. Starting with the Baltic countries the report moves to Scandinavia, further down to Central and Southern Europe, South-eastern Europe and then to the North Sea region, including the British Isles, the Low Countries and Western Germany. Let us call that the North Sea Crime Region. This does not reveal more than that each country has an 'organised crime' problem with its neighbouring countries or with countries with which it has linguistic or cultural connections. Thus, the Baltic has organised crime-trade with Russia, Finland and Sweden with the Baltic, Greece with Albania, Spain and Portugal with South America, etc. Only the strip of countries from Poland to Slovenia (the old 'Cordon Sanitaire' before the Second World War) is criminally more inward looking. Given this regional shape of the crime-markets, the conclusion that "OC is increasingly international in its composition" amounts to an obvious tautology. This is a truth which holds since the time that cross-country price differences stimulated underground trade of whatever commodity. And that is since time immemorial.

Some aspects of 'organised crime' which are recommended as points of special attention, are so obvious that the reader may be induced to read twice to make sure that he did not miss the reason of mentioning in the first place. He may feel assured, because there was no reason. Of course, the police must pay attention to the "ability [of OC groups] to communicate within and between each other." Well, the police do not need such an encouragement as it spends already most of its detective time on monitoring communications between criminals. This ability to communicate and the 'financial dimension' are parts of the functional side of 'organised crime.' To this functional side special attention should be devoted because "OC groups become increasingly fluid and difficult to address." Implicitly this is related to the criminals' "drive to make money without being caught." Yes, indeed, quite a revelation for the public. Not so obvious is the statement that the balance between money making and secrecy has tilted to money making and (or because) "the shielding activities of the OC groups are deemed sufficient enough to protect their continued activities, strategic leadership and assets." Does this mean that the enemy has become complacent? That should be the good news! Unfortunately the reader is left with this open question. 


\section{Old and new threats}

The most difficult part of the OCTA 2006 to evaluate is its core: the threat assessment. In the first place the structure of the report is such that it is difficult to attribute the various key factors to specific markets of potentially discernable criminal market players. In every mentioned key area threats are looming, and there is always some truth in it. In the second place it is not clear whether the spotted threats are based on serious empirical evidence or could have been devised by everyone with some knowledge of 'organised crime' and a bit of imagination. As far as the empirical foundations are concerned: there is no single reference to observed factual trends. Neither is there a differentiation between threats of all times and the development of new threats. Well, most threats are of all times, with the exception of internationalisation. That is a bit more recent crime furthering dimension, albeit when we measure in terms of decades.

This internationalisation is related to all sorts of cross-border operating foreign groups. This leads to the not surprising conclusion that according to OCTA 2006 the biggest threat comes from the "non-indigenous criminal groups': "In conclusion, the situation where a non-indigenous criminal group resorts to international operations and also aims at managing the distribution phase within the EU markets is the highest threat." It looks as if the repeated referring (17 times) to non-indigenous crimeentrepreneurs operating inside the EU from their home countries is an expression of xenophobia, which is not the case. Close reading may convince the reader that this focus on non-indigenous 'organised criminals' is based on the fear that these have a bigger chance of remaining beyond the reach of European law enforcement agencies. Granted, that is something no policeman can swallow.

Who are these internationally operating 'non-indigenals' who allegedly strive to control the whole chain of contraband trading, from source to the distribution phase? Some 15 years ago researchers identified 'integrated trading chains' in Turkish heroin trafficking crime-families as well as in Dutch cannabis wholesaler combines (hence an old threat) (Van Duyne 1996). However, these integrated trading lines proved to be vulnerable and have been dismantled. The crime-entrepreneurs learned the hard lesson: proper criminal risk management pointed rather at a 'slicing up' of the various phases of the traffic with less human factor management and less leaks. Hence, the transport was 'outsourced' and the distribution mainly left to itself. Without further specification this 'biggest threat' should be shelved unless solid evidence to the contrary is put forward.

According to OCTA 2006 this 'non-indigenous organised crime' threat from nonmember states may be amplified by the globalisation. This facilitates the combining of criminal resources, creates a community of reference in the EU and furthers the movement of (criminal) goods and services by these criminal 'non-indigenals'. Is there a threat of an 'untouchable criminal domination' beyond police control (in the EU)? However, that would only relate to the criminal (non-indigenous) suppliers. But contrary to this conclusion, Europol recognises (in another section) the regulating forces of the crime-markets which are inherently demand markets. "On the other hand, globalisation is transforming criminal markets to be dominated by buyers rather than sellers. It is increasingly easy to get hold of illegal goods or products needed for crime. This factor, a sort of globalisation of supply, could also favour 
indigenous OC groups, because it should erode or prevent monopoly positions of certain non-indigenous OC groups." This implies that globalisation is a counter force. That looks like good news. There is a twofold morale in this observation: (a) foster your indigenous organised crime groups, because they are less dangerous and should not be replaced by monopoly seeking 'non-indigenals'; (b) compared to the blind forces of the criminal demand markets, the law enforcement agencies are virtually powerless. Beware of the 'iron hand of the market,' particularly the shady and criminal one! That is an a-moral conclusion with far-reaching socio-economic implications in the direction of those agencies whose main drive is to disrupt those markets with unforeseen changes in the relationship between supply and demand. So, where does the threat actually originate? The 26 pages of OCTA 2006 are not meant for such subtleties. But the reader should be aware of some incoherence between the various threat projections of OCTA 2006.

\section{Who threatens?}

The lack of coherence and sharp line can also be observed in the elaboration of the criminal groups and the crime-markets. Granted, the report aims to make realistic differentiations and correctly deviates from traditional conceptions of hierarchically organised 'syndicates.' But subsequently confusion sets in as all the other purported 'organised criminals' must be subsumed under the heading of 'organised crime.' This is the political Procrustean bed which the OCTA-rapporteurs could not disregard, but which leads to quite a muddled presentation of the threatening organised criminal market players. The OCTA-rapporteurs point correctly at the huge variety of cooffenders: small groups, loose groups and ephemeral networks. The report even coins the concept of "individual 'organised criminal'," unfortunately-as so often-without further explanation or example. The report also indicates the apparent chaos in the criminal entrepreneurial market, which it qualifies as follows: "Structure exists also in the apparent chaos of changing patterns of criminal association." This should not be taken as an ironic paraphrase from Schopenhauer that there is system in the chaos. These are all correct observations, which ironically do only make sense outside the 'organised crime' Procrustean bed.

Some 'threats' are just a component of certain modus operandi. Naturally, any smuggling operation requires transportation. Hence, the transport sector is always threatened, now, in the future and in the past. The extent and nature of abusing the transport sector is determined by the nature and size of the cargo. As soon as the cargo becomes large and the smuggler needs a truck or a ship, he is bound to establish a (front) firm with licences, insurance, a trained driver, etc. The same applies to VAT scams: one must have a series of firms with a VAT number and given the nature of the VAT fraud, the trading must be cross-border with all the upperworld facilities.

Most of the threat observations, like the involvement of legal persons could just as well have been made 15 years ago. Specialist criminal service providers are also an old phenomenon: when the Dutch hash smugglers experienced the danger of

\footnotetext{
${ }^{1}$ However, in the OCTA 2007 questionnaire (which the author has not received) questions do refer to syndicates.
}

望 Springer 
managing the whole trading line, they left the risky and labour intensive transport to seasoned veterans who served various principals. The same applies to mechanics who prepared cars and ships.

The 'increasing' money launderer could likewise not be lacking in the row of threatening actors: "The trend to use specialist money launderers is increasing." Concerning this issue I invite the rapporteurs to become more specific. Doing research on 'criminal money management,' I do identify from time to time suspects, who really launder crime-money for third persons, but these were usually low level professionals. Having run out of luck and money they have become susceptible to crime-entrepreneurs' money, which hardly rates as something new. But most criminals are financially do-it-your-selvers, in the past and in the future, as the last thing they tend to do is entrusting someone else with their money. The rapport would really have contributed more to our knowledge if they would have been more specific on this so important issue.

In the end, somewhat unannounced, the report provides a categorisation of OC groups who may be a threat. The foundation of the categorisation is: those we cannot get and dismantle are more threatening than those who are less successful in this regard. The OCTA 2006 identifies:

- Principally territorially based, indigenous OC groups, with extensive transnational activities; especially such with possibilities to shield their leadership and assets even inside the EU;

- Mainly ethnically homogeneous groups with their leadership and main assets abroad;

- Dynamic networks of perpetrators, whose organisational setup is less viable to attack from a law enforcement perspective than their communications and finances;

- OC groups based on strictly defined organisational principles without an ethnic component, coupled with a large international presence.

The categories are considered as not mutually exclusive.

From a law enforcement perspective this categorisation has some potential. However, it should be elaborated and applied to specific 'groups' (ranging from the 'individual organised criminal,' via loose networks to strict hierarchies) on each differentiated market. What would be the rating of an alleged fraudster, who became prime minister and succeeded to defy law enforcement efforts because through corruption and patronage he had a servile parliament change the law? Making plausibly looking statements (without empirical reference) is one thing, putting them to the proper test by trying to refute them by empirical evidence is another.

The question 'who threatens' does not get further than a general categorisation with some potential, but otherwise remains floating in unspecified generalities and truisms.

\section{OCTA 2006 and other OC reports}

OCTA 2006 does not stand alone. There are many other organised crime reports, though they do not carry the title of 'threat assessment'. Is the OCTA 2006 a better law enforcement product than other reports? When we look at one of the national 
organised crime (situation) reports, such as the Bundeskriminalamt Lagebild and a non-EU organised crime like the one recently published by the State of Oregon, there are some similarities and differences.

The German 2005 Organised Crime Situation Report is a solid piece of statistics, which is tantalising for the reader who wants to know more than a series of mere frequencies, tables or the wrong central indexes (the arithmetic mean instead of the median in cases of a non-normal distribution). The report is a skeleton without theory or any higher presumptions, something like an annual statistical account of imports and exports or agricultural products. The percentages of some variables go a few points up (for example German perpetrators), of others go a few points down. The presented material should have been broken down to unfold the information potential underlying this shallow presentation. And what does it tell us about 'organised crime?' Actually very little. We observe a number of sketchy lines of various crime-markets in which business goes on as usual, with occasional variations, like some shifts in the drug markets and the usual cross-border traffic with the neighbouring countries, predominantly The Netherlands.

The Oregon 'organised crime' assessment report describes many criminal areas, ranging from drug trafficking, motor cycle gangs, Asian and Eurasian organisations to 'ecoterrorists' and extremist hate groups. The report provides sufficient details so that the reader can obtain a proper overview of the various crime areas. It is modest as far as projections of looming threats are concerned, though it could have been somewhat more daring about this subject. Nevertheless, it is highly informative.

Interestingly, this report can be read outside the whole 'organised crime' paradigm and still be understood, which underlines the redundancy of the organised crime concept. It just describes criminal organisations, like the drug trading organisations, for which it poses a higher threshold than the EU: an Oregon drug trafficking organisation consists of five or more persons and must have a clearly defined hierarchy. (For other organised crime groups, like the Asian and Eurasian crime groups, such thresholds are not proposed.) If one wants to deduce threats, one can connect one to each discernable offender group, like the increasing activities of Mexican traffickers or the Animal Liberation Front. But there is no would-be overarching 'organised crime' conceptuology. This makes it a refreshing reading.

\section{Conclusion}

Given the previous discussion, how should OCTA 2006 be valued and according to what criteria?

The prime criteria are those which the rapporteurs themselves use. According to the head of Europol OCTA 2006 was an example of a core product of intelligence led policing and one of Europol top priorities in 2006. Here, one becomes curious at the meaning of 'intelligence based policing,' while I invite the political masters of Europol to have a closer look at the other, apparently lower ranking Europol priorities. The reader can at any rate deduce that in this case the phrase 'intelligence led' does not mean: 'evidence based.'

The reader may think that behind this public version there is the 'real' OCTA 2006. Otherwise, there is no point in speaking of a 'public' version. This proves to be 
a deception: there is no background 'real' OCTA 2006. This text is all there is. Representatives of 25 European police forces have been working hard, processing secret questionnaires to obtain only a 'public version' with a predominance of either stale news or enormities like: criminals are increasingly using information technology to shield their communications (while their kids are designing their own programmes to dodge their parents electronic filter programmes). ${ }^{2}$ One may wonder how the contents of this threat assessment may contribute in fulfilling the promise of "closing the gap between strategic findings and operational activities." With the exception of identified crime regions (a positive point), nothing is specific enough of closing any gap.

This lack of specification becomes the more irksome as one general statement of irrefutable truism about threats and unspecified threatening OC groups is followed by another. One may wonder what image the rapporteurs have of the readers' educational level when these are supposed to feel informed by statements like: "OC groups will continue to exploit new market opportunities?"

We leave aside the question whether Europol as an institution is to blame, as it is bound by directives from the political level, and it depends on the input from the Member States. It can collate, but not create this input. But Europol could evoke a reliable input by using a proper research instrument. This raises the question we started with: where is that instrument and how does it look like? Here we are stonewalled: the methodology is confidential, as has been agreed upon by the Member States. Europol (and the Member States) does not stand alone in this obvious breach of public accountability and transparency. In all organised crime situation reports or threat assessments, the methodological justification is treated in a worse than stepmotherly way (Van Duyne and Van Dijck 2007). The excuses put forward to justify this secrecy, namely that it may inform criminals or may endanger police actions, are too thin to be taken seriously. No criminal may learn anything from an empty questionnaire and a methodology is not about police operations. Stating that the assessment is 'qualitative' rather than quantitative is a poor substitute for democratic accountability which is clearly under threat.

It should be noted that OCTA 2006 contains more notions of modern criminological research than one finds in most other organised crime reports. But where are the references and how have the literature sources been used? This remains obscure too, with which I arrive at the more fundamental final question: should such assessments actually be the task of Europol (or other law enforcement agencies) in the first place? In terms of costs-benefits it is certainly costly undertaking with a most debatable yield. As OCTA 2007 appears to be finalised already - with another confidential and disputable questionnaire, and this time with a non-public background report—we should look at OCTA 2008 to open the debate on this issue.

\footnotetext{
${ }^{2}$ This implies that the contributing Member States have been as badly informed as all other readers.
} 


\section{References}

van Duyne PC (1996) The phantom and threat of organized crime. Crime, Law \& Social Change 24 (4):341-377

van Duyne PC, van Dijck M (2007) Assessing organised crime: The sad state of an impossible art. In: Bovenkerk F, Levi M (eds) The organized crime community: essays in honor of Alan A. Block. Springer, New York 